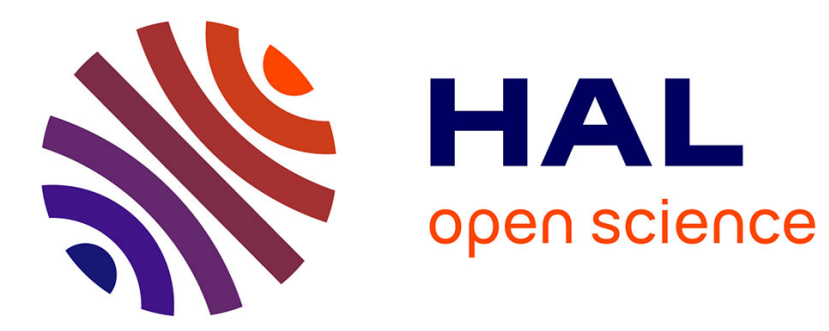

\title{
Evidence for functional GABAA but not GABAC receptors on mouse cone photoreceptors
}

\author{
Sercan Deniz, Eric Wersinger, Serge Picaud, Michel J Roux
}

\section{To cite this version:}

Sercan Deniz, Eric Wersinger, Serge Picaud, Michel J Roux. Evidence for functional GABAA but not GABAC receptors on mouse cone photoreceptors. Visual Neuroscience, 2019, 36, pp.E005. 10.1017/S0952523819000038 . hal-02342212

\section{HAL Id: hal-02342212 \\ https://hal.science/hal-02342212}

Submitted on 31 Oct 2019

HAL is a multi-disciplinary open access archive for the deposit and dissemination of scientific research documents, whether they are published or not. The documents may come from teaching and research institutions in France or abroad, or from public or private research centers.
L'archive ouverte pluridisciplinaire HAL, est destinée au dépôt et à la diffusion de documents scientifiques de niveau recherche, publiés ou non, émanant des établissements d'enseignement et de recherche français ou étrangers, des laboratoires publics ou privés. 
3 Sercan DENIZ ${ }^{1-4 a}$, Eric WERSINGER ${ }^{1-4 b}$, Serge PICAUD ${ }^{5}$, Michel J. ROUX ${ }^{1-4 \S}$

5 1) Institut de Génétique et de Biologie Moléculaire et Cellulaire, Illkirch, France

6 2) Centre National de la Recherche Scientifique, UMR7104, Illkirch, France

7 3) Institut National de la Santé et de la Recherche Médicale, U1258, Illkirch, France

8 4) Université de Strasbourg, Illkirch, France

9

5) Sorbonne Université, INSERM, CNRS, Institut de la Vision, 17 rue Moreau, F-75012 Paris, France

§ To whom correspondence should be addressed. Email: mjroux@igbmc.fr

${ }^{\text {a }}$ Present address: Department of Ophthalmology, Feinberg School of Medicine, Northwestern

${ }^{\text {b }}$ Present address: Facultés de Médecine et de Pharmacie, UMR INSERM/UCA 1107-Neuro-Dol, 28

Pages: 25

Tables: 0

Figures: 4 


\section{Abstract:}

At the first retinal synapse, horizontal cells contact both photoreceptor terminals and bipolar cell dendrites, modulating information transfer between these two cell types to enhance spatial contrast and mediate color opponency. The synaptic mechanisms through which these modulations occur are still debated. The initial hypothesis of a GABAergic feedback from horizontal cells to cones has been challenged by pharmacological inconsistencies. Surround antagonism has been demonstrated to occur via a modulation of cone calcium channels through ephaptic signaling and $\mathrm{pH}$ changes in the synaptic cleft. GABAergic transmission between horizontal cells and cones has been reported in some lower vertebrates like the turtle and tiger salamander. In these reports, GABA is released from horizontal cells through reverse transport and target GABA receptors are located on cone terminals. In mammalian retinas, there is growing evidence that horizontal cells can release GABA through conventional vesicular transmission, acting both on autaptic GABA receptors and on receptors expressed at the dendritic tips of bipolar cells. The presence of GABA receptors on mammalian cone terminals remains equivocal. Here, we looked specifically for functional GABA receptors on mouse photoreceptors by recording in the whole-cell or amphotericin/gramicidin perforated patch-clamp configurations. Cones could be differentiated from rods through morphological criteria. Local GABA applications evoked a $\mathrm{Cl}^{-}$current in cones but not in rods. It was blocked by the $\mathrm{GABA}_{\mathrm{A}}$ receptor antagonist bicuculline methiodide and unaffected by the GABAc receptor antagonist TPMPA. The voltage dependency of the current amplitude was as expected from a direct action of GABA on cone pedicles, but not from an indirect modulation of cone currents following the activation of the GABA receptors of horizontal cells. This supports a direct role of GABA release from horizontal cells in the control of cone activity in the mouse retina.

Keywords: GABA, feedback, cone photoreceptor, horizontal cell 


\section{INTRODUCTION}

Our ability to detect edges in the visual world is enhanced through a process called lateral inhibition, mediated by horizontal cells (HCs) which exert both a negative (Baylor et al., 1971) and a positive (Jackman et al., 2011) feedback onto cone photoreceptors. The underlying synaptic mechanisms are still not fully understood. Inconsistencies in the pharmacology and ions underlying the negative feedback current have challenged the initial hypothesis of a GABAergic transmission between HCs and cones (reviewed in Piccolino, 1995; Thoreson \& Mangel, 2012). A modulation of cone calcium channels (Verweij et al., 1996, 2003), by either hemichannel-mediated ephaptic communication (Kamermans et al., 2001; Pottek et al., 2003; Fahrenfort et al., 2009; Klaassen et al., 2011; Kemmler et al., 2014) or through pH changes in the synaptic cleft (Hirasawa \& Kaneko, 2003; Davenport et al., 2008; Wang et al., 2014) has arisen as the main mechanism for the negative feedback. Far from being mutually exclusive, both ephaptic and $\mathrm{pH}$ modulations are likely to shape cone calcium signals (Kemmler et al., 2014).

Many of the molecular and physiological underpinnings required for a GABAergic transmission from HCs to cones are however present in various species. On the presynaptic side, in lower vertebrates, GABA can be released in a $\mathrm{Ca}^{2+}$-independent manner via membrane transporters (Schwartz, 1987). In the mammalian outer retina, the vesicular transporter VGAT/VIAAT was localized in HC tips in mouse, guinea pig, human and macaque retinas (Haverkamp et al., 2000; Cueva et al., 2002; Jellali et al., 2002; Guo et al., 2010); HCs were reported to express the synaptic proteins required for vesicular release in rabbit and guinea pig (Hirano et al., 2005; Lee \& Brecha, 2010). Though HCs were previously reported not to contain GABA in rodents (Agardh et al., 1986; VersauxBotteri et al., 1989; Fletcher \& Kalloniatis, 1997), we have demonstrated that this was due to GABA loss during tissue preparation, that could be compensated by supplementing the medium with a GABA precursor, such as glutamine or glutamate, and with pyridoxal phosphate, a cofactor of the glutamate acid decarboxylases (Deniz et al., 2011). Preventing GABA release from HCs by targeted 
deletion of VGAT removed the feedback to cone photoreceptors (Hirano et al., 2016), possibly through an autaptic action of GABA on $\mathrm{HCs}$, changing the membrane permeability to $\mathrm{HCO}_{3}{ }^{-}$and hence affecting the $\mathrm{pH}$ in the synaptic cleft (Liu et al., 2013). If GABA receptors are expressed in cone terminals, they could modulate cone output both by influencing directly the membrane potential and by affecting the $\mathrm{pH}$ in the synaptic cleft, as those expressed on HCs.

On the postsynaptic side, while the presence of GABA receptors on cone terminals has been reported in many lower vertebrates (reviewed in Wu, 1992), it remains controversial regarding mammalian cones. In situ hybridization in rat showed signal in the ONL for $\beta_{1}$ but not for several other subunits of $\mathrm{GABA}_{\mathrm{A}}$ receptors $\left(\alpha_{1-4}, \beta_{2-3}, \gamma_{2}\right.$ et $\delta$ ) (Greferath et al., 1993, 1995). $\beta_{1}$ and $\beta_{2}$ mRNA were detected in the rat ONL by PCR (Grigorenko \& Yeh, 1994). In situ hybridization for the GABA $\alpha_{1}$ subunit was also negative in the rabbit retina (Brecha et al., 1991). $\alpha$ and $\beta$ subunits were detected in cone pedicles but not in rod spherules by immunohistochemistry in the cat (Vardi et al., 1992).

Further electron microscopy studies in macaque and rabbit retinas suggested that the GABA receptor subunit staining in the OPL might be attributed solely to the strongly labelled bipolar cell dendritic tips (Vardi \& Sterling, 1994; Greferath et al., 1994). $\alpha_{1}$ and $\rho$ subunits were not detected in mouse cones by immuno electron microscopy (Kemmler et al., 2014). A GABA-evoked current was detected in only a fraction of cones in macaque flatmount retina, without pharmacological characterization (Verweij et al., 2003); both $\mathrm{GABA}_{\mathrm{A}}$ and $\mathrm{GABA}_{C}$ receptors were reported by combining electrophysiology and immunohistochemistry in porcine cones in culture (Picaud et al., 1998) and in putative mouse cones from flatmount $r d 1$ retinas or dissociated from WT C57BL/6J retinas (Pattnaik et al., 2000). These apparent discrepancies may be due to variations between species, a difficult path for GABA to reach the cone terminals in WT flatmounts, low levels of expression of GABA receptor subunits in mammalian cones, difficulty in identifying dissociated cones, and/or changes in expression during retinal degeneration or in culture. To circumvent those issues, we have assessed directly the presence of GABA receptors in photoreceptors on acute slices of adult mouse retinas, using either whole-cell or perforated patch clamp recordings. 


\section{MATERIAL AND METHODS}

\section{Retinal slice preparation}

Procedures involving animals and their care were conducted in agreement with the ARVO Statement for the Use of Animals in Ophthalmic and Vision Research, the French Ministry of Agriculture and the European Community Council Directive no. 86/609/EEC, OJL 358. Mice strains used in this study were either C57BL/6J or Balb/c ByJ bred at the Mouse Clinical Institute animal house (IIlkirch, France). As results from both strains were similar, results were pooled together. Mice were maintained on a 12h/12h light-dark cycle, with light ON from 7 AM to 7 PM. Light-adapted, adult (9-19 weeks) mice were killed by cervical dislocation in the morning (9-10 AM). The eyes were enucleated and immediately put in ice-cold bicarbonate-buffered saline (BBS), composed of (in $\mathrm{mM}$ ): $\mathrm{NaCl} 126, \mathrm{KCl}$ 2.5, $\mathrm{CaCl}_{2} 2.4, \mathrm{MgCl}_{2} 1.2, \mathrm{NaH}_{2} \mathrm{PO}_{4} 1.2, \mathrm{NaHCO}_{3} 18$, glucose 11 previously bubbled with $95 \% \mathrm{O}_{2} / 5 \%$ $\mathrm{CO}_{2}$. The cornea, lens and vitreous were removed. The retina was detached from the pigmented epithelium and embedded in agarose $1.5 \%$ prepared in PBS $(0.1 \mathrm{M} ; \mathrm{pH} 7.4)$ kept at $42^{\circ} \mathrm{C}$. After agarose solidification on ice, the retina was cut in 150 or $200 \mu \mathrm{m}$ thick slices using a Leica VT1000S vibratome (Leica, Wetzlar, Germany). The slices were kept at room temperature in bubbled BBS for at least half an hour before recording, in normal lighting conditions.

\section{Patch-clamp recordings}

Slices were observed under infrared differential interference contrast (DIC) using a 63x objective and a C8484 camera (Hamamatsu, Massy, France) on a Leica DMLFS microscope (Leica, Wetzlar, Germany). The preparation was continuously perfused at $\sim 2 \mathrm{ml} /$ minute with bubbled BBS. Pipettes (6-8 M $\Omega$ ) were pulled from GC150TF borosilicate glass capillaries (Harvard Apparatus, Les Ulis, France) on a horizontal puller (DMZ Universal Puller, Zeitz Instrumente, Munich, Germany). Two different intracellular solutions were used: one containing (in $\mathrm{mM}$ ) $\mathrm{KCl} 42, \mathrm{~K}$ gluconate $98, \mathrm{EGTA}-\mathrm{Na}_{4}$ $10, \mathrm{MgCl}_{2} 1$, HEPES 5, ATP- $\mathrm{Na}_{2} 5\left(\mathrm{E}_{\mathrm{Cl}}=-28.9 \mathrm{mV}\right.$, junction potential of $12.4 \mathrm{mV}$, referred to in the text as $\left.\mathrm{E}_{\mathrm{Cl}}=-29 \mathrm{mV}\right)$ or $\mathrm{KCl} 138, \mathrm{EGTA}^{-\mathrm{Na}_{4}} 10, \mathrm{MgCl}_{2} 3, \mathrm{CaCl}_{2} 1, \mathrm{HEPES} 10$, ATP-Na 2 3, GTP-Na $30.5\left(\mathrm{E}_{\mathrm{Cl}}=\right.$ 
$11.9 \mathrm{mV}$, junction potential of $3.9 \mathrm{mV}$, referred to in the text as $\mathrm{E}_{\mathrm{Cl}}=2 \mathrm{mV}$ ). For perforated patch

2 recordings, amphotericin $B(80-180 \mu \mathrm{g} / \mathrm{ml})$ or gramicidin $(80-100 \mu \mathrm{g} / \mathrm{ml})$ was added to the pipette

3 solution from a $120 \mathrm{mg} / \mathrm{ml}$ stock solution in DMSO. All solutions contained $10 \mu \mathrm{M}$ of Alexa Fluor ${ }^{\circledR}$

4 (488 or 594) hydrazide (Molecular Probes, Eugene, OR), and pH was adjusted to 7.4 with $\mathrm{NaOH}$. The

5 extracellular solution was the BBS described above, continuously bubbled with $95 \% \mathrm{O}_{2} / 5 \% \mathrm{CO}_{2}$.

6 Potentials were corrected post-recording for the calculated junction potential. For simplicity,

7 potentials indicated in the text are rounded to integer values. All experiments were performed at room temperature $\left(20-25^{\circ} \mathrm{C}\right)$, between $11 \mathrm{AM}$ and $8 \mathrm{PM}$ for the successful cone recordings, with no evident circadian variation (Supplementary Figure 4). Data were acquired using a Multiclamp 700A amplifier, a Digidata 1322A interface and the pClamp9 software (Molecular Devices, Sunnyvale, CA).

Data were filtered prior to digitization at a frequency of $1 / 2$ or $1 / 5$ th of the acquisition frequency, which was $200 \mathrm{~Hz}$ for puffed GABA ( $\gamma$-aminobutyric acid) and $10 \mathrm{kHz}$ for depolarizing pulse experiments. Agonists were applied locally with a puffer pipette connected to a Picospritzer III (Parker Hannifin, Fairfield, NJ) and antagonists were applied via bath application. TPMPA $((1,2,5,6-$ Tetrahydropyridin-4-yl)methylphosphinic acid) was obtained from Tocris (Ellisville, MI), all others chemicals were obtained from Sigma-Aldrich (Lyon, France). All values are indicated as mean \pm S.E.M. 


\section{RESULTS}

\section{Targeting cone photoreceptors on mouse retinal slices}

To determine if mouse photoreceptors express functional GABA receptors, we recorded from cones and rods in the whole-cell patch-clamp configuration, on acute slices from mouse retinas. Cones, which represent only $3 \%$ of the photoreceptor population in mice (Jeon et al., 1998), have slightly larger and more oval cell bodies than rods. This morphological difference allowed for a partially targeted rather than "blind" cone recording. Although most of the cone cell bodies were located close to the outer limiting membrane (Fig. 1A), some of them were also found close to the OPL (Fig. 1B). As an Alexa dye was included in the pipette solution, cone identity could be confirmed at the end of the recording by visualizing the synaptic terminal, as previously reported by Cangiano et al.(2012). Cone pedicles (Fig. 1A-C, supplementary figure 1) are much larger than the small rounded terminals of rods (Fig. 1D-E, supplementary figure 2). The long outer segment of rods (Fig. 1D-E, supplementary figure 3) was also more readily observed than the shorter one from cones. While the formation of a gigaseal could be readily obtained with both types of photoreceptors, most of the cells were lost when attempting to go into the whole-cell configuration, possibly due to the fact that the nucleus occupies most of the cell soma volume. Some rods were recorded after contacting them at the level of the inner segment (Fig. 1D), which allowed for an easier transition to whole-cell mode. Some recordings were obtained using amphotericin B perforated-patch, which allowed for a higher success rate than whole-cell patch. Cone identity could be confirmed by dye diffusion after membrane rupture at the end of the recording.

To compare the responses to GABA applications in cones with and without terminals, we needed a criterion to distinguish the latter from terminal-lacking rods. To this end, we compared the current-voltage (I-V) relationships obtained from photoreceptors. We have more specifically focused on I-V curves recorded with the $\mathrm{E}_{\mathrm{Cl}}=-29 \mathrm{mV}$ pipette solution during $100 \mathrm{~ms}$ voltage steps, conditions for which we had the most cells in the different categories. For well-identified, terminal-bearing 
photoreceptors, currents evoked by voltage steps above $-50 \mathrm{mV}$ were larger in cones than in rods (Fig. 2A-D), as were the following tail currents (Fig. 2A-C, E) (13 rods and 11 cones in D and E), requiring in some cones over a second to fully de-activate after a 100 ms depolarizing step (Fig. 2C). These currents were similar to the chloride currents described in cones from the larval tiger salamander (Barnes \& Bui, 1991) and the ground squirrel (Szmajda \& DeVries, 2011). The depolarization-evoked current was maximal at $+26 \mathrm{mV}$ (Fig. 2D), while the tail current peaked when returning from a step to $+6 \mathrm{mV}$ (Fig. 2E). The individual values of these currents are represented in Figure 2 F-G, distinguishing five groups of cells. Cones $(n=11)$ and rods $(n=13)$ that could be identified through the morphology of their synaptic terminal are represented with green and grey symbols, respectively. Rods identified as such through the presence of a typical outer segment but with no visible synaptic terminal are represented with orange symbols $(n=11)$. The remaining cells were tagged either as putative cones (red symbols, $n=8$ ) or putative rods (cyan symbols, $n=5$ ) depending on the shape of their soma as observed prior to recording - oval for cones (see stars in Fig.1B), rounded for rods. The presence of a short outer segment was not used to tag cones, as such a segment could correspond to a damaged/collapsed rod outer segment. For both types of currents, the range of amplitudes were comparable between identified and putative cones, and between identified and putative rods (Fig. 2F). However, there was some overlap between the cone and rod populations, thus neither the plateau nor tail current amplitude alone could be used to unambiguously identify as cones some of the terminal-less cells. When considering both currents together, there was very little overlap between the cone and rod populations, all identified and putative rods being included in the range $\left[I_{\text {tail }}<100 \mathrm{pA}, I_{\text {plateau }}<350 \mathrm{pA}\right]$, while all but one of the identified and putative cones were outside this range (Fig. 2G).

Cones response to GABA applications

GABA (1 mM) was puffed nearby the synaptic terminal of the recorded photoreceptors (5 to 250 ms duration). A GABA-evoked current was detected in 34 out of 35 cones with pedicles. The 
amplitude of the current evoked by a 100 ms puff of 1 mM GABA on 14 pedicle-bearing cones recorded with the $\mathrm{E}_{\mathrm{Cl}}=2 \mathrm{mV}$ intracellular solution ranged between -12.5 and $-166 \mathrm{pA}$ at $-64 \mathrm{mV}$ $(-51.4 \pm 46.5 \mathrm{pA}, \mathrm{n}=14)$ (Fig. 3A; left). As GABA was applied onto the surface of the slice, the current amplitude was at least in part dependent upon the depth of the pedicle in the slice. Notably, a cone with an intact morphology but with a pedicle deeper than $30 \mu \mathrm{m}$ (estimated from the epifluorescence focus) did not respond to GABA when puffed on the slice surface, but responded when the puff pipette was dipped into the slice. As the response kinetics were similar to those of other cones after GABA puffs on the slice surface, it was most probably a true response to GABA rather than a mechanical artifact. No GABA-evoked current was detected from cells tentatively identified as pedicle-less cones through the current amplitude criteria presented in Figure $2 G(n=4)$, in line with a GABA receptor localization restricted to the synaptic terminal, as in turtle retina (Tachibana \& Kaneko, 1984). No current was evoked in rods either (Fig. 3A, right), whether they had their spherule $(n=7)$ or not $(n=8)$. This was an additional control against a possible mechanical puffinduced response. Bicuculline methiodide $(100 \mu \mathrm{M})$ blocked $87.5 \pm 3.2 \%(n=11)$ of the GABA evoked current (Fig. 3B, left). For cells in which bicuculline methiodide did not fully block the response to GABA, the presence of the antagonist did not change the kinetics of the GABA-evoked current, as can be seen in Figure $3 \mathrm{C}$, which presents both the raw traces (left) and currents normalized to their peak (right). This suggests that the remaining current corresponds to an incomplete blockade, rather than to a kinetically slower $G A B A_{c}$ component. Consistent with this hypothesis, the $G A B A_{c}$ antagonist TPMPA $(50 \mu \mathrm{M})$ had little effect (Fig. 3B, right) on the GABA-induced current with a mean blockade of $4.7 \pm 4.7 \%(n=3)$. We could not systematically apply both inhibitors, as most of the cone recordings were short-lived. As expected for currents mediated by ionotropic GABA receptors, the GABA-evoked current reversed at a potential close to the $\mathrm{Cl}^{-}$equilibrium potential $\left(E_{c I}\right)$ : when $E_{C l}$ was set at $-29 \mathrm{mV}$, the current reversed at $-30.3 \pm 4.1 \mathrm{mV}\left(\mathrm{n}=5\right.$, Fig. 3D). When $\mathrm{E}_{\mathrm{Cl}}$ was set at $2 \mathrm{mV}$, the current reversed at $0.7 \pm 1.7 \mathrm{mV}(\mathrm{n}=7$, Fig. $3 \mathrm{E})$. 
assess this parameter, we used gramicidin perforated-patch recordings. The success rate of such recordings on cones was very low. In 4 cells with adequate intracellular access, GABA evoked very small currents $(-3.4 \pm 1.7 \mathrm{pA}$ at $-94 \mathrm{mV},-1.5 \pm 0.8 \mathrm{pA}$ at $-64 \mathrm{mV})$. It is probable than these cells were cones rather than rods, as in whole-cell, we did not record any GABA response from identified rods (0/7) in opposition to cones (34/35), as mentioned above. The GABA-evoked current changed linearly with the membrane potential, reversing at $-36.9 \pm 6.3 \mathrm{mV}(\mathrm{n}=4$, Fig. $3 \mathrm{~F})$. .

\section{DISCUSSION}

There is contradictory evidence for the presence of functional GABA $A_{A}$ receptors on cone synaptic terminals, depending on species. $\mathrm{GABA}_{\mathrm{A}}$ receptor-mediated currents were reported in many lower vertebrates, including in the turtle (Kaneko \& Tachibana, 1986) and the salamander (Wu, 1986). Atypical ionotropic $G A B A$ receptors as well as $G A B A_{B}$ receptors were detected in the bullfrog retina (Liu et al., 2005, 2006). There are however very few published electrophysiological recordings from mammalian cones. Small GABA responses were detected in only a fraction of macaque cones on flatmount retinas (5/12), with a polarity matching the one expected for a $\mathrm{Cl}^{-}$current in 4 out of the 5 responding cones (Verweij et al., 2003). No pharmacology was performed to determine if those responses could be due to the activation of GABA receptors. Large $G A B A_{A}$ and $G A B A_{C}$ currents were recorded both in primary culture of pig cones (Picaud et al., 1998), and on putative mouse cones, either on flatmount $r d 1$ mouse retinas or dissociated from C57BL/6J retinas (Pattnaik et al., 2000).

We report here for the first time, in morphologically identified cones on acute mouse retinal slices, the presence of GABA-evoked currents with a $\mathrm{GABA}_{\mathrm{A}}$ pharmacology. Cone identification was obtained through the inclusion of a morphological dye into the patch pipette, allowing the visualization of the large cone synaptic terminal. Moreover, cones with terminals displayed currents comparable to the calcium-activated chloride currents / glutamate transporter currents detected in 
cones from other species (Barnes \& Hille, 1989; Verweij et al., 2003; Szmajda \& DeVries, 2011). As no synaptic transmission blocker was present in our recording conditions, the GABA-evoked current could correspond to a secondary current following a GABA action on horizontal cell, as observed in the rat retina (Liu et al., 2013) rather than a direct effect on $\mathrm{GABA}_{A}$ receptors present on cone pedicles. It is however unlikely: the recorded current was reversing close to $\mathrm{E}_{\mathrm{Cl}}$ with a voltagedependence not compatible with a modulation of the activation curve of cone calcium channels. If that was the case, the maximum effect would have occurred in the -35 to $-45 \mathrm{mV}$ range, and minimal effect at potentials bellow $-60 \mathrm{mV}$ or over $0 \mathrm{mV}$. However, the maximal (absolute) amplitude of the GABA-evoked currents was systematically recorded at the most negative potential tested, which was between -102 and -64 mV depending on the recording conditions (Fig. $3 \mathrm{D}-\mathrm{F}$ ). In addition, outward currents could be recorded above $0 \mathrm{mV}$ for many cones. The most likely explanation is thus that functional $G A B A_{A}$ (and not $G A B A_{C}$ ) receptors are expressed on mouse cone pedicles. While such a conclusion would have been expected some decades ago when lateral inhibition was considered to result from a GABAergic inhibition of cones, it is now dissonant with a number of published studies, either on the presence of functional GABA receptors on mammalian cone pedicles or on the indirect response of cones to GABA, mediated by horizontal cells.

The apparent discrepancy between our results and the reported presence of both $\mathrm{GABA}_{\mathrm{A}}$ and $\mathrm{GABA}_{C}$ currents in cultured pig cones (Picaud et al., 1998) and in mouse cones from flatmount $r d 1$ retinas or freshly dissociated from C57BL/6J retinas (Pattnaik et al., 2000) can be tentatively explained. In the former case, it could come either from a difference between mouse and pig cones, or a partial dedifferentiation of pig cones after 2 to 10 days in culture. In flatmount $r d 1$ retinas, cone identity was deduced from the localization in the thin remaining outer nuclear layer at an age at which most rods have degenerated. The recording of both $\mathrm{GABA}_{\mathrm{A}}$ and $\mathrm{GABA}_{C}$ currents, larger than the $G A B A_{A}$-only current reported here, could thus be due to a partial dedifferentiation of cones, or to morphological rearrangements occurring during degeneration, with the presence of bipolar cells at the distal surface of the degenerated $r d 1$ retinas. The former hypothesis is supported by 
transcriptome studies from $r d 1$ cones at more advanced ages (110-220 days), suggesting that the GABAc $\rho_{1}$ and $\rho_{2}$ subunit mRNAs are expressed by surviving cones (Busskamp et al., 2010) (see also GEO Series GSE22338). The latter is consistent with the current-voltage relationships of the recorded cells, reminiscent of those of rod bipolar cells. The four freshly dissociated cells from C57BL/6J retinas considered as cones in the same report, may similarly have been bipolar cells with partially damaged/collapsed processes, morphologically close to cones once their pedicle and inner/ outer segments have collapsed, which occurs quickly after dissociation - their current-voltage relationships are also matching those from rod bipolar cells, both in kinetics and in amplitude.

Besides these initial reports, more recent studies suggest that mammalian cones do not express GABA receptors. The lack of a systematic GABA response of macaque cones on flatmount retinas (Verweij et al., 2003), seconded by similar results from David Schneeweis obtained on macaque retinal slices (personnal communication reported in Verweij et al., 2003), indicate that macaque cones do not consistently respond, directly or indirectly, to GABA applications. Similarly, GABA-evoked current were not detected in ground squirrel cones, over a large range of potentials (-110 to $+40 \mathrm{mV}$, Sercan Deniz and Steven DeVries, personal communication). In rat (Liu et al., 2013) and mouse (Kemmler et al., 2014) retinal slices, the effect of GABA on cone calcium signals is not direct but occurs through horizontal cells. In the macaque retina, as surround antagonism was observed in only $20 \%$ of the cones (Verweij et al., 2003), the lack of an indirect action of GABA on cones in macaque (and ground squirrel) could be due to the lability of the secondary mechanism relaying horizontal cell membrane potential changes to cones in these species. This mechanism could be more robust in rodent retinas, allowing for a more reliable detection of responses in rat and mouse cones - however not in our case. Both Liu et al. (2013) and Kemmler et al. (2014) prepared slices using a tissue chopper, while we used agarose embedding and vibratome sectioning. Even if it is slower and possibly more mechanically demanding on the tissue due to the blade vibrations, it shouldn't weaken the horizontal cell to cone contact sufficiently to prevent feedback. Studies that did not detect an indirect GABA effect on mammalian cones (Verweij et al., 2003, David Schneeweiss, 
Steven DeVries, ours) used patch-clamp recordings of cone currents, while those which did (Liu et al., 2013; Kemmler et al., 2014) relied on calcium imaging. The indirect effect is expected to be mediated by $\mathrm{pH}$ changes in the synaptic cleft (Liu et al., 2013), as well as by hemichannels (Kemmler et al., 2014), both resulting in a modulation of the calcium channel activation curve. Whole-cell recordings of cones may perturb this indirect effect, due to the run-down of calcium channel currents. However, we recorded some cones using amphotericin (crossed symbols in Fig. 3E) or gramicidin-perforated patch (Fig. 3F), which should better preserve calcium channel activity over the time course of the experiments. Those cones responded to GABA similarly to those recorded in whole-cell configuration, with no sign of a non-linearity in the potential range affecting calcium channel activation. Another difference between our conditions and those of Liu et al. (2013) and Kemmler et al. (2014) is that we used fully light-adapted retinas. This could tentatively explain the discrepancy between their results and ours, as lateral inhibition is affected by the ambient light level and the light-adaptation state of the retina (reviewed in Thoreson \& Mangel, 2012). In Kemmler et al. (2014), the conclusion that "GABA is unlikely acting directly at the [mouse] cone terminal, but instead may modulate cone output by controlling other feedback mechanisms", was based 1) on the fact that the observed changes in calcium signal evoked by GABA puffs in cone pedicles were in contrast to what is expected from a GABAergic inhibition, and 2) on the lack of immunostaining for $\alpha_{1}$ and $\rho_{1}$ subunits. Neither of these arguments can rule out the presence of $\mathrm{GABA}_{\mathrm{A}}$ receptors on cone pedicles: 1) the direct action of $\mathrm{GABA}$ on cones depends on $\mathrm{E}_{\mathrm{Cl}}$, which most reports point as close to the dark potential: - $34 \mathrm{mV}$ in the salamander (Thoreson \& Bryson, 2004), -31 mV in the ground squirrel (Szmajda \& DeVries, 2011), -37 mV in the putative mouse cones we recorded in the gramicidin perforated-patch configuration. Only a small change in membrane potential is thus expected from the activation of GABA receptors. Moreover, this effect could be masked by the indirect effect mediated by horizontal cells. 2) the presence of the $\alpha_{1}$ subunit is not required to have functional $\mathrm{GABA}_{\mathrm{A}}$ receptors(reviewed in Olsen \& Sieghart, 2008). 

GABA receptor subunits in rabbit cones during the night (Mangel S, et al. IOVS 2013;54:ARVO E-

Abstract 404, Mangel S, et al. IOVS 2015;56:ARVO E-Abstract 1340, Mangel S, IOVS 2016;57:ARVO EAbstract 588). There was however no recording from rabbit cones to demonstrate that this increase is associated with the presence of functional receptors on the cone terminals. While rabbits are endogenously nocturnal animals, they become predominantly diurnal in animal-house conditions (Jilge, 1991). Thus, similar circadian changes in receptor expression may explain the absence of GABA-evoked current in macaque and ground squirrel cones during the day. Nocturnal animals as rats and mice could be expected to have opposed variations, with $\mathrm{GABA}_{\mathrm{A}}$ receptor expression during the day. Our GABA responses recordings from mouse cones were obtained during the day (12PM - 8 PM), with no evidence of a circadian influence on the current amplitude (Supplementary Figure 4). This time period may have been too short to detect it, but it should also be kept in mind that both mouse lines used in this study are melatonin-deficient (Ebihara et al., 1986), which may prevent circadian changes in receptor expression.

Since the initial demonstration of horizontal cell to cone negative feedback in the vertebrate retina (Baylor et al., 1971), identifying the underlying mechanism(s) has been an active field of research. There is now growing evidence that lateral inhibition results from the compound action of various pathways modulating the $\mathrm{pH}$ in the synaptic cleft (Vroman et al., 2014; Warren et al., 2016a), including horizontal cell GABA receptors (Liu et al., 2013), together with an ephaptic mechanism (Kamermans et al., 2001; Kamermans \& Fahrenfort, 2004; Warren et al., 2016b; reviewed in Thoreson \& Mangel, 2012; Chapot et al., 2017). The causes of many apparent discrepancies have been progressively identified, but many others still have to be understood. Regarding the influence of GABA on cone responses to center-surround illumination, a confounding factor may have been the low capacity of horizontal cells to counteract the GABA loss happening during retinal harvesting for electrophysiology, as described in the mouse retina (Deniz et al., 2011). This may apply to other species, including those with both a well-established GABAergic nature of horizontal cells and 
expression of GABA receptors on cone terminals, as the turtle. If a GABA-dependent feedback was detected only in presence of pentobarbital in slices (Tatsukawa et al., 2005), it may be occurring more robustly in vivo. Besides discrepancies, it is unclear why a diversity of modulatory mechanisms coexist in the horizontal cell to cone synapse, or in other words what is the exact contribution of each mechanism depending on the type of stimuli. It is notably hard to predict the role of cone GABA receptors. As mentioned above, many reports indicate that the cone $\mathrm{E}_{\mathrm{Cl}}$ is close to the dark potential: opening or closing of GABA receptors in response to changes in the GABA release from horizontal cells should then have little direct effect on the cone membrane potential. This effect will be more substantial when the cone $\mathrm{E}_{\mathrm{Cl}}$ is more negative than the dark potential, as in the turtle or the goldfish (Kaneko \& Tachibana, 1986; Kraaij et al., 2000). As cones are graded-potential neurons, even small changes in membrane potential can change the glutamate release. GABA receptors could also contribute through their influence on the synaptic cleft $\mathrm{pH}$, as proposed for those of horizontal cells (Liu et al., 2013), through their permeability to $\mathrm{HCO}_{3}{ }^{-}$. Changes in intracellular $\mathrm{Cl}^{-}$may also affect release, either through the modulation of calcium channels (Thoreson et al., 2000; Babai et al., 2010) or through changes in osmotic tension (Chavas et al., 2004). 
1 Acknowledgements: This work was supported by Human Frontier Science Program grant

2 RGY0004/2003 to MJR, Fédération des Aveugles de France to SD, Association Française contre les

3 Myopathies SAFM05-002 to EW, ANR GABARET to SP, and ANR-10-LABX-0030-INRT, a grant from a

4 French State fund managed by the Agence Nationale de la Recherche under the frame program

5 Investissements d'Avenir ANR-10-IDEX-0002-02, CNRS, INSERM, Université Pierre and Marie Curie,

6 Assistance Publique-Hôpitaux de Paris. We thank Dr. Steve DeVries for his comments on the initial

7 version of this manuscript.

8

9 Abbreviations:

10 BBC: bicarbonate-buffered saline

11 DIC: Differential Interference Contrast

12 GABA: $\gamma$-amino butyric acid

13 GCL: ganglion cell layer

14 HC: horizontal cell

15 INL: inner nuclear layer

16 ONL: outer nuclear layer

17 OPL: outer plexiform layer

18 TPMPA: (1,2,5,6-Tetrahydropyridin-4-yl)methylphosphinic acid 
Agardh E, Bruun A, Ehinger B \& Storm-Mathisen J (1986). GABA immunoreactivity in the retina. Invest Ophthalmol Vis Sci 27, 674-678.

Babai N, Kanevsky N, Dascal N, Rozanski GJ, Singh DP, Fatma N \& Thoreson WB (2010). Anionsensitive regions of L-type CaV1.2 calcium channels expressed in HEK293 cells. PLOS ONE 5, e8602.

Barnes S \& Bui Q (1991). Modulation of calcium-activated chloride current via $\mathrm{pH}$-induced changes of calcium channel properties in cone photoreceptors. J Neurosci 11, 4015-4023.

Barnes S \& Hille B (1989). Ionic channels of the inner segment of tiger salamander cone photoreceptors. J Gen Physio/ 94, 719-743.

Baylor DA, Fuortes MG \& O'Bryan PM (1971). Receptive fields of cones in the retina of the turtle. J Physiol (Lond) 214, 265-294.

Brecha NC, Sternini C \& Humphrey MF (1991). Cellular distribution of L-glutamate decarboxylase (GAD) and gamma-aminobutyric acid $A\left(G A B A_{A}\right)$ receptor mRNAs in the retina. Cell Mol Neurobiol 11, 497-509.

Busskamp V, Duebel J, Balya D, Fradot M, Viney TJ, Siegert S, Groner AC, Cabuy E, Forster V, Seeliger M, Biel M, Humphries P, Paques M, Mohand-Said S, Trono D, Deisseroth K, Sahel JA, Picaud S \& Roska B (2010). Genetic reactivation of cone photoreceptors restores visual responses in retinitis pigmentosa. Science $\mathbf{3 2 9}, \mathbf{4 1 3}-417$.

Cangiano L, Asteriti S, Cervetto L \& Gargini C (2012). The photovoltage of rods and cones in the darkadapted mouse retina. J Physiol (Lond) 590, 3841-3855.

Chapot CA, Euler T \& Schubert T (2017). How do horizontal cells 'talk' to cone photoreceptors? Different levels of complexity at the cone-horizontal cell synapse. J Physiol (Lond) 595, 54955506.

Chavas J, Forero ME, Collin T, Llano I \& Marty A (2004). Osmotic Tension as a Possible Link between $\mathrm{GABA}_{\mathrm{A}}$ Receptor Activation and Intracellular Calcium Elevation. Neuron 44, 701-713.

Cueva JG, Haverkamp S, Reimer RJ, Edwards R, Wässle H \& Brecha NC (2002). Vesicular gammaaminobutyric acid transporter expression in amacrine and horizontal cells. J Comp Neurol 445, 227-237.

Davenport CM, Detwiler PB \& Dacey DM (2008). Effects of pH buffering on horizontal and ganglion cell light responses in primate retina: evidence for the proton hypothesis of surround formation. J Neurosci 28, 456-464.

Deniz S, Wersinger E, Schwab Y, Mura C, Erdelyi F, Szabó G, Rendon A, Sahel J-A, Picaud S \& Roux MJ (2011). Mammalian retinal horizontal cells are unconventional GABAergic neurons. J Neurochem 116, 350-362.

Ebihara S, Marks T, Hudson DJ \& Menaker M (1986). Genetic control of melatonin synthesis in the pineal gland of the mouse. Science 231, 491-493. 
Fahrenfort I, Steijaert M, Sjoerdsma T, Vickers E, Ripps H, van Asselt J, Endeman D, Klooster J, Numan $\mathrm{R}$, ten Eikelder H, von Gersdorff H \& Kamermans M (2009). Hemichannel-mediated and $\mathrm{pH}$ based feedback from horizontal cells to cones in the vertebrate retina. PLOS ONE 4, e6090.

Fletcher EL \& Kalloniatis M (1997). Localisation of amino acid neurotransmitters during postnatal development of the rat retina. J Comp Neurol 380, 449-471.

Greferath U, Grünert U, Fritschy JM, Stephenson A, Möhler H \& Wässle H (1995). GABA A receptor subunits have differential distributions in the rat retina: in situ hybridization and immunohistochemistry. J Comp Neuro/ 353, 553-571.

Greferath U, Grünert U, Müller F \& Wässle H (1994). Localization of $\mathrm{GABA}_{A}$ receptors in the rabbit retina. Cell Tissue Res 276, 295-307.

Greferath U, Müller F, Wässle H, Shivers B \& Seeburg P (1993). Localization of GABA $A$ receptors in the rat retina. Vis Neurosci 10, 551-561.

Grigorenko EV \& Yeh HH (1994). Expression profiling of $\mathrm{GABA}_{\mathrm{A}}$ receptor beta-subunits in the rat retina. Vis Neurosci 11, 379-387.

Guo C, Hirano AA, Stella SL Jr, Bitzer M \& Brecha NC (2010). Guinea pig horizontal cells express GABA, the GABA-synthesizing enzyme GAD 65, and the GABA vesicular transporter. J Comp Neurol 518, 1647-1669.

Haverkamp S, Grünert U \& Wässle H (2000). The cone pedicle, a complex synapse in the retina. Neuron 27, 85-95.

Hirano AA, Brandstätter JH \& Brecha NC (2005). Cellular distribution and subcellular localization of molecular components of vesicular transmitter release in horizontal cells of rabbit retina. $J$ Comp Neurol 488, 70-81.

Hirano AA, Liu X, Boulter J, Grove J, Pérez de Sevilla Müller L, Barnes S \& Brecha NC (2016). Targeted Deletion of Vesicular GABA Transporter from Retinal Horizontal Cells Eliminates Feedback Modulation of Photoreceptor Calcium Channels. eNeuro; DOI: 10.1523/ENEURO.014815.2016 .

Hirasawa H \& Kaneko A (2003). pH changes in the invaginating synaptic cleft mediate feedback from horizontal cells to cone photoreceptors by modulating $\mathrm{Ca}^{2+}$ channels. J Gen Physiol 122, 657671.

Jackman SL, Babai N, Chambers JJ, Thoreson WB \& Kramer RH (2011). A positive feedback synapse from retinal horizontal cells to cone photoreceptors. PLoS Biol 9, e1001057.

Jellali A, Stussi-Garaud C, Gasnier B, Rendon A, Sahel J-A, Dreyfus H \& Picaud S (2002). Cellular localization of the vesicular inhibitory amino acid transporter in the mouse and human retina. J Comp Neurol 449, 76-87.

Jeon C-J, Strettoi E \& Masland RH (1998). The Major Cell Populations of the Mouse Retina. J Neurosci 18, 8936-8946.

Jilge B (1991). The rabbit: a diurnal or a nocturnal animal? J Exp Anim Sci 34, 170-183. 
Kamermans M \& Fahrenfort I (2004). Ephaptic interactions within a chemical synapse: hemichannelmediated ephaptic inhibition in the retina. Curr Opin Neurobiol 14, 531-541.

Kamermans M, Fahrenfort I, Schultz K, Janssen-Bienhold U, Sjoerdsma T \& Weiler R (2001). Hemichannel-mediated inhibition in the outer retina. Science 292, 1178-1180.

Kaneko A \& Tachibana M (1986). Effects of gamma-aminobutyric acid on isolated cone photoreceptors of the turtle retina. J Physiol (Lond) 373, 443-461.

Kemmler R, Schultz K, Dedek K, Euler T \& Schubert T (2014). Differential regulation of cone calcium signals by different horizontal cell feedback mechanisms in the mouse retina. J Neurosci 34, 11826-11843.

Klaassen L, Sun Z, Steijaert MN, Bolte P, Fahrenfort I, Sjoerdsma T, Klooster J, Claassen Y, Shields CR, Ten Eikelder HMM, Janssen-Bienhold U, Zoidl G, McMahon DG \& Kamermans M (2011). Synaptic transmission from horizontal cells to cones is impaired by loss of connexin hemichannels. PLoS Biol 9, e1001107.

Kraaij DA, Spekreijse H \& Kamermans M (2000). The Nature of Surround-Induced Depolarizing Responses in Goldfish Cones. J Gen Physiol 115, 3-16.

Lee H \& Brecha NC (2010). Immunocytochemical evidence for SNARE protein-dependent transmitter release from guinea pig horizontal cells. Eur J Neurosci 31, 1388-1401.

Liu J, Li G-L \& Yang X-L (2006). An ionotropic GABA receptor with novel pharmacology at bullfrog cone photoreceptor terminals. Neurosignals 15, 13-25.

Liu J, Zhao J-W, Du J-L \& Yang X-L (2005). Functional GABA(B) receptors are expressed at the cone photoreceptor terminals in bullfrog retina. Neuroscience 132, 103-113.

Liu X, Hirano AA, Sun X, Brecha NC \& Barnes S (2013). Calcium channels in rat horizontal cells regulate feedback inhibition of photoreceptors through an unconventional GABA- and $\mathrm{pH}$ sensitive mechanism. J Physiol (Lond) 591, 3309-3324.

Olsen RW \& Sieghart W (2008). International Union of Pharmacology. LXX. Subtypes of $y^{-}$ Aminobutyric Acid A Receptors: Classification on the Basis of Subunit Composition, Pharmacology, and Function. Update. Pharmacol Rev 60, 243-260.

Pattnaik B, Jellali A, Sahel J, Dreyfus H \& Picaud S (2000). GABA $c$ receptors are localized with microtubule-associated protein $1 B$ in mammalian cone photoreceptors. J Neurosci 20, 67896796.

Picaud S, Pattnaik B, Hicks D, Forster V, Fontaine V, Sahel J \& Dreyfus H (1998). GABA $A$ and GABA receptors in adult porcine cones: evidence from a photoreceptor-glia co-culture model. $J$ Physiol (Lond) 513, 33-42.

Piccolino M (1995). The feedback synapse from horizontal cells to cone photoreceptors in the vertebrate retina. Prog Retin Eye Res 14, 141-196.

Pottek M, Hoppenstedt W, Janssen-Bienhold U, Schultz K, Perlman I \& Weiler R (2003). Contribution of connexin26 to electrical feedback inhibition in the turtle retina. J Comp Neurol 466, 468477. 
Schwartz EA (1987). Depolarization without calcium can release gamma-aminobutyric acid from a retinal neuron. Science 238, 350-355.

Szmajda BA \& DeVries SH (2011). Glutamate Spillover between Mammalian Cone Photoreceptors. J Neurosci 31, 13431-13441.

Tachibana M \& Kaneko A (1984). gamma-Aminobutyric acid acts at axon terminals of turtle photoreceptors: difference in sensitivity among cell types. Proc Natl Acad Sci USA 81, 79617964.

Tatsukawa T, Hirasawa H, Kaneko A \& Kaneda M (2005). GABA-mediated component in the feedback response of turtle retinal cones. Vis Neurosci 22, 317-324.

Thoreson WB \& Bryson EJ (2004). Chloride equilibrium potential in salamander cones. BMC Neurosci $5,53$.

Thoreson WB \& Mangel SC (2012). Lateral interactions in the outer retina. Prog Retin Eye Res 31, 407-441.

Thoreson WB, Nitzan R \& Miller RF (2000). Chloride efflux inhibits single calcium channel open probability in vertebrate photoreceptors: chloride imaging and cell-attached patch-clamp recordings. Vis Neurosci 17, 197-206.

Vardi N, Masarachia P \& Sterling P (1992). Immunoreactivity to $G A B A_{A}$ receptor in the outer plexiform layer of the cat retina. $J$ Comp Neurol 320, 394-397.

Vardi N \& Sterling P (1994). Subcellular localization of $G A B A_{A}$ receptor on bipolar cells in macaque and human retina. Vision Res 34, 1235-1246.

Versaux-Botteri C, Pochet R \& Nguyen-Legros J (1989). Immunohistochemical localization of GABAcontaining neurons during postnatal development of the rat retina. Invest Ophthalmol Vis Sci 30, 652-659.

Verweij J, Hornstein EP \& Schnapf JL (2003). Surround antagonism in macaque cone photoreceptors. J Neurosci 23, 10249-10257.

Verweij J, Kamermans M \& Spekreijse H (1996). Horizontal cells feed back to cones by shifting the cone calcium-current activation range. Vision Res 36, 3943-3953.

Vroman R, Klaassen L, Howlett MHC, Cenedese V, Klooster J, Sjoerdsma T \& Kamermans M (2014). Extracellular ATP Hydrolysis Inhibits Synaptic Transmission by Increasing pH Buffering in the Synaptic Cleft. PLoS Biol 12, e1001864.

Wang T-M, Holzhausen LC \& Kramer RH (2014). Imaging an optogenetic pH sensor reveals that protons mediate lateral inhibition in the retina. Nat Neurosci 17, 262-268.

Warren TJ, Hook MJ, Supuran CT \& Thoreson WB (2016a). Sources of protons and a role for bicarbonate in inhibitory feedback from horizontal cells to cones in Ambystoma tigrinum retina. J Physiol (Lond) 594, 6661-6677.

Warren TJ, Hook MJV, Tranchina D \& Thoreson WB (2016b). Kinetics of Inhibitory Feedback from Horizontal Cells to Photoreceptors: Implications for an Ephaptic Mechanism. J Neurosci 36, 10075-10088. 
1 Wu SM (1986). Effects of gamma-aminobutyric acid on cones and bipolar cells of the tiger $2 \quad$ salamander retina. Brain Res 365, 70-77.

3 Wu SM (1992). Feedback connections and operation of the outer plexiform layer of the retina. Curr 4 Opin Neurobiol 2, 462-468.

5 


\section{FIGURE LEGENDS}

2 Figure 1: Distinguishing cones from rods through their morphology. (A-B) Superposition of DIC

images from retinal slices and fluorescence images, and fluorescence images only, of recorded cones, filled with Alexa Fluor 488. Cones had an oval soma $(\mathrm{s})$ and a large terminal $(\mathrm{t})$. Stars $\left({ }^{*}\right)$ indicate putative cone somas. (C) Confocal image from a cone filled with Alexa Fluor 488 acquired after recording. (D-E) Superposition of DIC images from retinal slices and fluorescence images, and fluorescence images only, of recorded rods, filled with either Alexa Fluor 488 or 594 . The smaller rounded somas and terminals contrast with those of cones. Scale bars: $10 \mu \mathrm{m}$ in C, $20 \mu \mathrm{m}$ in other panels.

Figure 2: Electrophysiological signature of cones and rods. (A-B) Representative currents evoked by voltage-jumps in a cone (A) and in a rod (B), from a holding potential of $-74 \mathrm{mV}$, with $100 \mathrm{~ms}$ steps to potentials ranging from $+46 \mathrm{mV}$ to $-134 \mathrm{mV}$ by $20 \mathrm{mV}$ decrements $\left(\mathrm{E}_{\mathrm{Cl}}=-29 \mathrm{mV}\right.$ intra-pipette solution). The magenta horizontal bar indicates the period considered to measure the "plateau" current, as plotted in D, F and G; the green arrow indicates the time at which the tail current was measured, 13 ms after repolarization, as plotted in panels E, F and G. (C) Currents evoked by voltagejumps in a cone as in $\mathrm{A}$, with a longer time scale to show the full deactivation of the $\mathrm{Ca}^{2+}$-dependent

$\mathrm{Cl}^{-}$current. The interval between steps was $10 \mathrm{~s}$ to allow for a full deactivation of this current. (D) Current-voltage relationship of the current evoked by 100 ms voltage jumps, from a holding potential of $-74 \mathrm{mV}$, to potentials ranging from $+46 \mathrm{mV}$ to $-134 \mathrm{mV}$ by $10 \mathrm{mV}$ decrements ( $E_{\mathrm{cl}}=-29 \mathrm{mV}$ intrapipette solution), measured from 97 to 99 ms following depolarization, for morphologically identified rods (black circles, $n=13$ ) and cones (open circles, $n=11$ ). (E) Current-voltage relationship of the tail current measured $13 \mathrm{~ms}$ after returning to the holding potential of $-74 \mathrm{mV}$, following $100 \mathrm{~ms}$ voltage jumps to potentials ranging from $+46 \mathrm{mV}$ to $-134 \mathrm{mV}$ by $10 \mathrm{mV}$ decrements $\left(E_{C l}=-29 \mathrm{mV}\right.$ intrapipette solution), for rods (black circles, $n=13$ ) and cones (open circles, $n=11$ ). (F-G) Individual 
values of the "plateau" current measured at $+26 \mathrm{mV}(\mathrm{F})$ or the tail-current measured after a depolarization at $+6 \mathrm{mV}(\mathrm{G})$ for rods (grey symbols when spherule is present, $\mathrm{n}=13$; orange symbols for rods for which no spherule could be seen at the end of the recording but identified as rods through their external segment, $n=11$ ), putative rods (cyan symbols, for cells considered as putative rods due to their soma appearance prior to patching, $n=5$ ), cones (green symbols, presence of a pedicle, $n=11$ ) or putative cones (red symbols, cells for which no pedicle could be seen at the end of the recording, but with a soma appearance suggestive of a cone prior to recording, $n=8$ ).

Triangles are used for rods in which an intact outer segment could be identified at the end of the recording, circles are used for other cells. The dotted line delimits the $\left[I_{\text {tail }}<100 \mathrm{pA}, I_{\text {plateau }}<350 \mathrm{pA}\right]$ range, which includes all identified and putative rods, and only one of the identified or putative cones.

Figure 3: Cone responses to GABA have a GABA ${ }_{A}$ pharmacology. (A) Puff application of GABA (100 $\mathrm{ms}, 1 \mathrm{mM}$ ) in the vicinity of a photoreceptor terminal evoked a current in cones (left) but not in rods (right). The holding potential was $-74 \mathrm{mV}$, as in B and C. (B) Cone responses to puff application of GABA (100 ms, 1 mM, control trace in black) were blocked by $100 \mu \mathrm{M}$ bicuculline methiodide (left, red trace) but not by $50 \mu \mathrm{M}$ TPMPA (right, blue trace). Traces obtained following wash out of the applied drug are shown in grey. (C) As in B, but for a cone which GABA response was not fully blocked by $100 \mu \mathrm{M}$ bicuculline methiodide (left, red trace). The right panel represents the traces from the left panel normalized to their peak, showing that the remaining component has the same kinetics as the control and wash currents. (D-E) Currents evoked by GABA reversed close to $E_{C l}$, whether it was set close to $-29 \mathrm{mV}$ (D, 5 cells) or $2 \mathrm{mV}$ ( $\mathrm{E}, 6$ cells), depending on the intrapipette solution. The calculated $E_{C l}$ is represented by a red line for reference. Each cell is plotted with a given color and distinct symbols linked by a dashed line. (F) GABA-evoked currents as a function of membrane potentials for 
14 cones recorded using gramicidin perforated patch. Data points of a given cell are linked by a dashed

2 line; solid lines are linear regressions to the data points.

3

4 

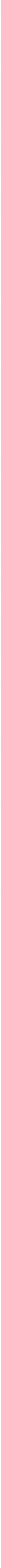

Os is $s=t$ 


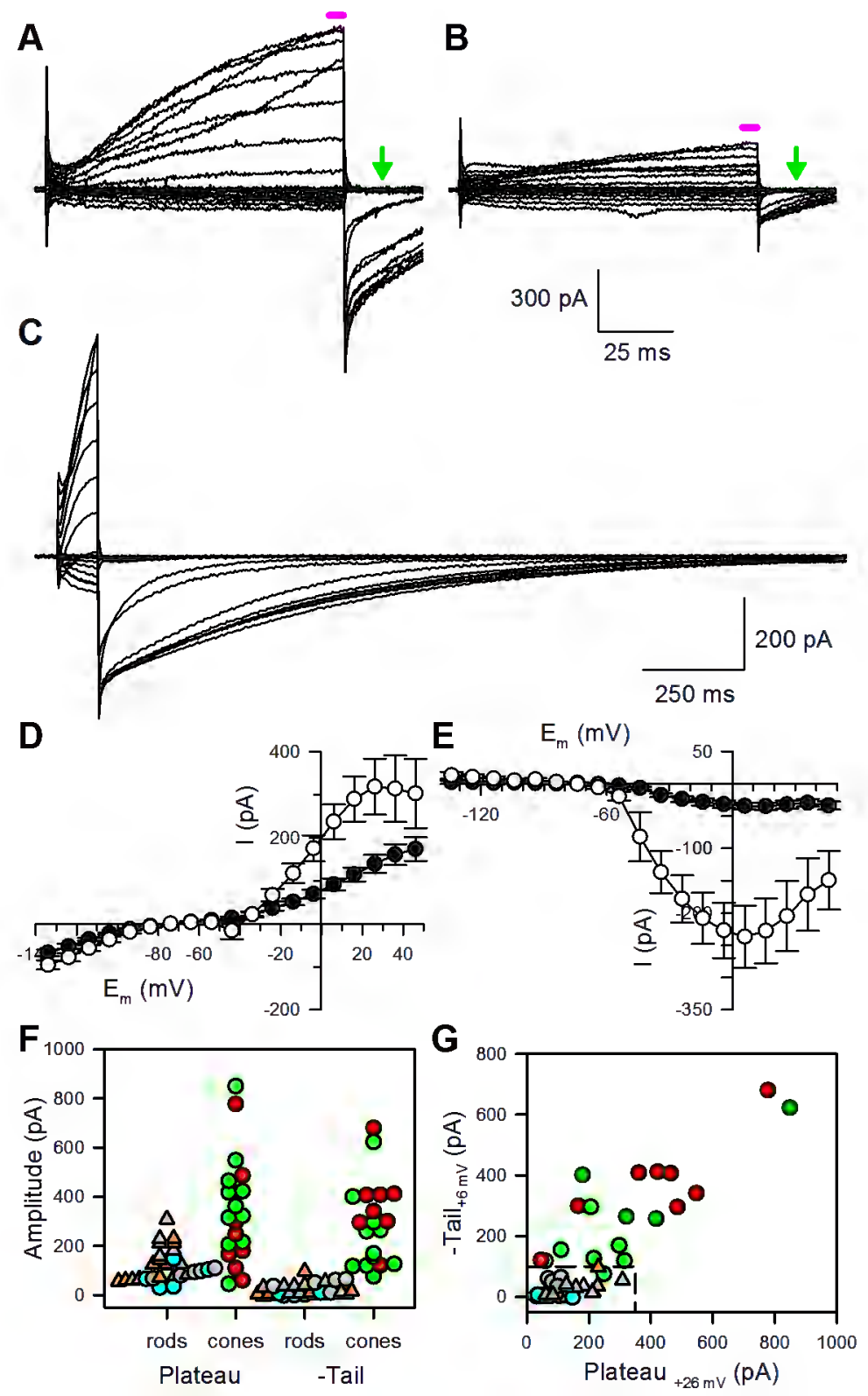



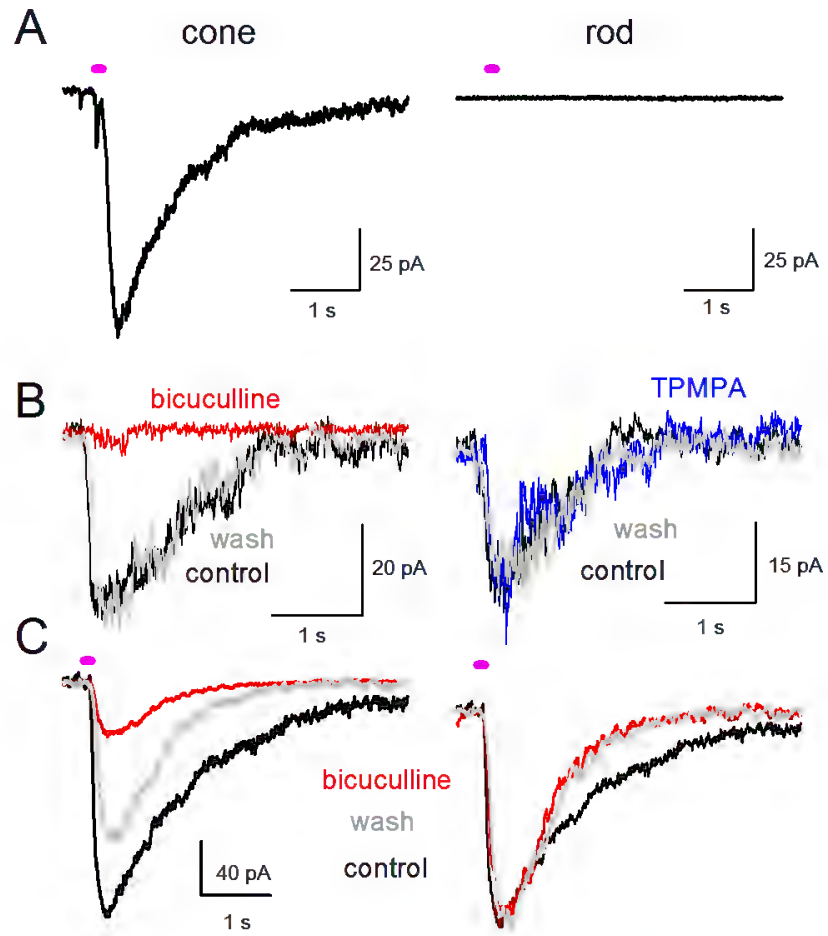

D

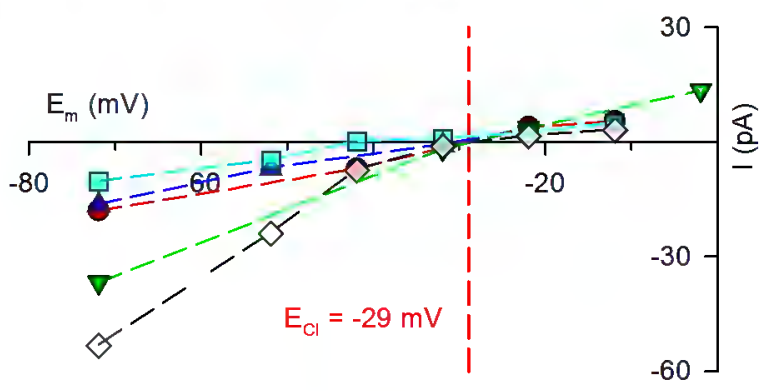

E

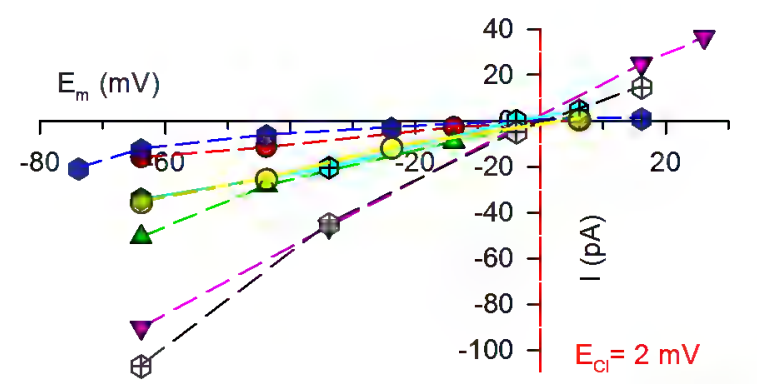

F

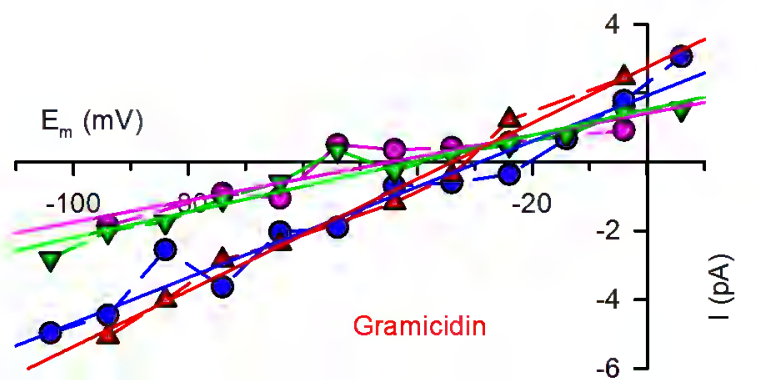




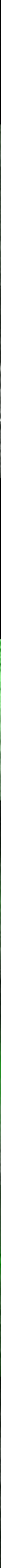


1

2

- 3

4

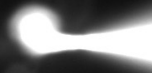

5

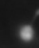

7

•

9

d b

6

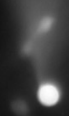

*

8

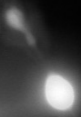

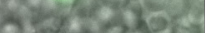
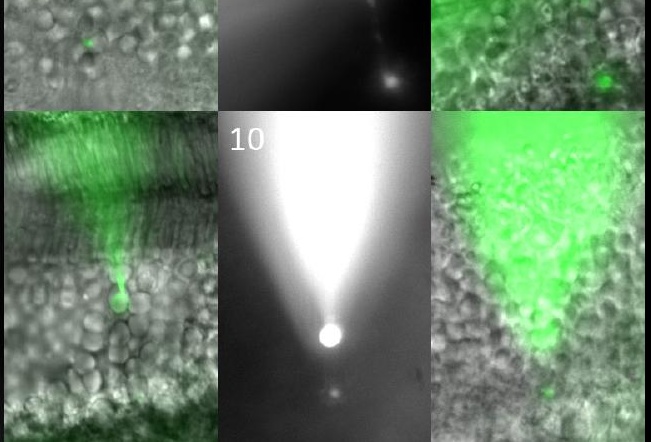

8




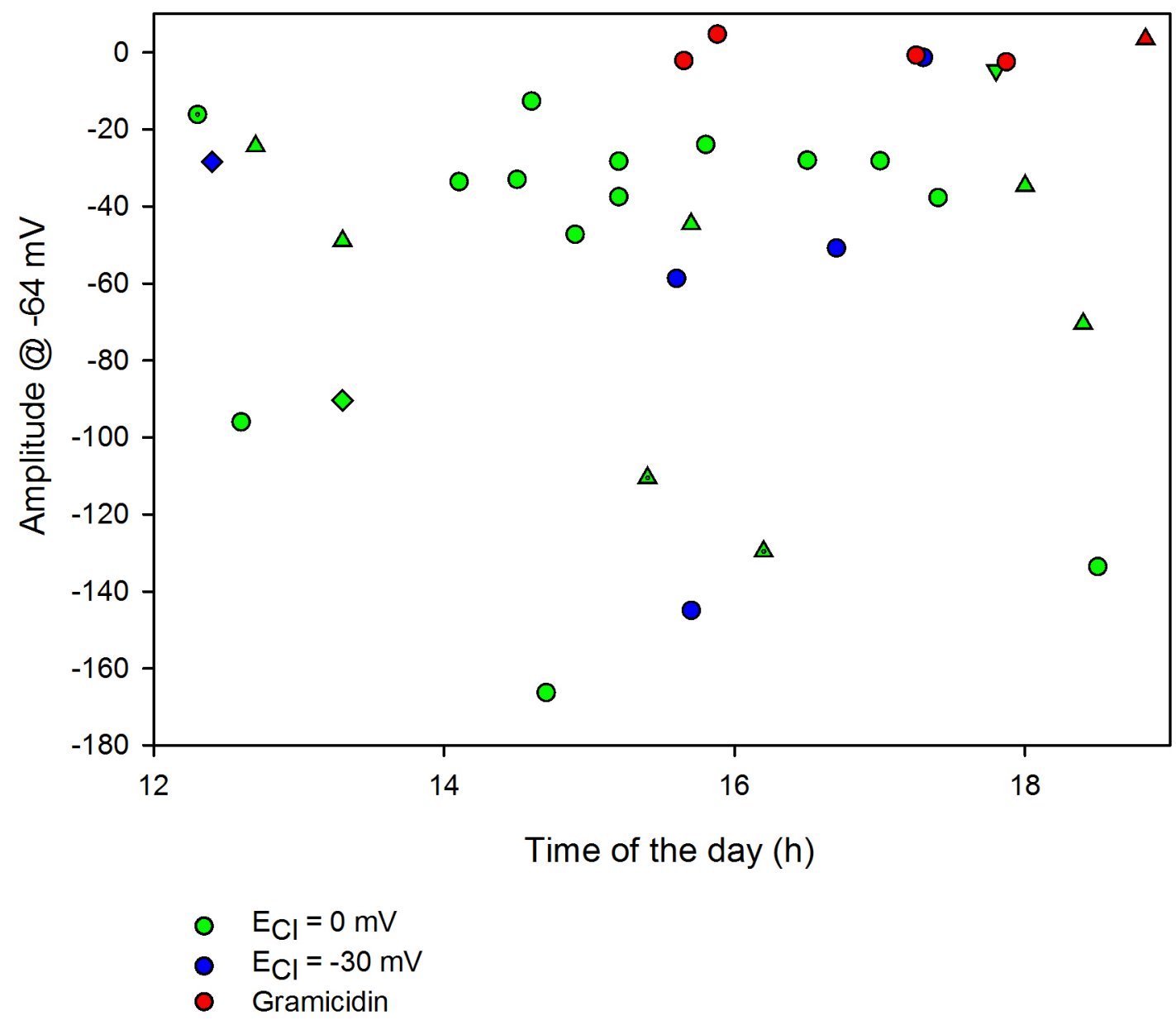


Legends of Supplementary Figures

\section{Supplementary Figure 1: Cones with pedicle}

Morphology of 16 recorded cones with their pedicle, obtained through the inclusion of an Alexa dye in the intrapipette solution. For cones 1,2 and 8,, images taken at different depth of focus are represented. For 13 of them, superimposition with a DIC image of the ONL/OPL is also presented. Scale bar in 16: $30 \mu \mathrm{m}$.

\section{Supplementary Figure 2: Rods with spherule}

Morphology of ten recorded rods with their spherule. For rods 2 and 3, the image was taken after retrieval of the patch pipette, to which the cell soma remained attached. In 6 , a cone previously recorded is labeled with $a^{*}$, next to the brighter rod.

\section{Supplementary Figure 3: Rods with outer segment but without spherule}

Morphology of 14 recorded rods identified through the presence of a long, thin outer segment, but which had lost their spherule during the slicing process.

Supplementary Figure 1: Amplitude of the GABA-evoked current as a function of the time of recording.

Amplitude of the current evoked by a 1 mM GABA puff of duration 5-10 ( $\diamond), 50(\triangle), 100(O)$ or 250 $\mathrm{ms}(\nabla)$. Recordings were obtained with intrapipette solutions with $\mathrm{E}_{\mathrm{Cl}}=-30 \mathrm{mV}$ (blue symbols) or $\mathrm{E}_{\mathrm{Cl}}$ $=0 \mathrm{mV}$ (green symbols, open for while-cell, dotted symbols for amphotericin perforated patch). For cones not recorded with the $\mathrm{E}_{\mathrm{Cl}}=0 \mathrm{mV}$ intracellular solution, the current amplitude was corrected for the difference in driving force. Recordings obtained using gramicidin perforated patch are indicated by red symbols, and were left uncorrected 